\title{
Computed tomographic demonstration of calcification of the ligamenta flava of the lumbosacra spine in ankylosing spondylitis
}

\author{
ELIESER AVRAHAMI, I' IRENA WIGLER, ${ }^{2}$ DORIT STERN, \\ DAN CASPI, ${ }^{2}$ AND MICHAEL YARON ${ }^{2}$
}

From the Departments of ${ }^{1}$ Radiology and ${ }^{2}$ Rheumatology, Sourasky Medical Center, and Tel-Aviv Universit Sackler School of Medicine, Israel

SUMMARY An axial computed tomographic (CT) scan of the lumbosacral regions was performed in 65 patients. The patient population was divided into two groups. The first (control) group $\vec{p}$ included 40 elderly patients without calcification of the ligamenta flava. The second groug included 25 patients with ankylosing spondylitis. More than $90 \%$ of those in the second grou showed calcified lumbosacral ligamenta flava. In two patients these calcifications produced spinall stenosis. The diagnostic and practical importance of these findings are discussed.

Calcification of the ligamentum flavum was first recognised in $1929 .{ }^{1}$ Only recently, however, was it found that such calcifications induced myelopathy. ${ }^{2} 3$ Since then similar reports have been presented, most of which referred to the location of this condition in the thoracic spine, producing myelopathy. ${ }^{4-7}$ Some of the reported cases, included mainly in the morphological studies, were associated with calcification and ossification of other spinal ligaments and enlargement of the vertebral pedicles. ${ }^{8}$ In his study on spinal column specimens, Hiraoka reported ossification of the ligamentum flavum in 44 out of $128(34 \%)$ spinal columns of cadavers of aged persons. ${ }^{9}$ Calcification and ossification of the ligamenta flava in the cervical spine, associated or not with myelopathy and radiculopathy, have also been reported. In several of the patients operations resulted in significant improvement. Cervical ligamenta flava calcifications have been found not rarely in elderly women as an incidental finding. ${ }^{10-17}$

Calcifications of the ligamenta flava in the lumbosacral spine have been reported as part of the spectrum of ligamentous calcifications of the entire spine. The condition seems poorly understood and has not been reported separately.

\section{Patients and methods}

Sixty five patients underwent axial CT scan of the Accepted for publication 19 June 1987.

Correspondence to Dr Elieser Avrahami, Department of Radiology, Sourasky Medical Center, Ichilov Hospital, 64239 Tel-Aviv, Israel. lumbosacral region (L3-S1). The patients were divided into two groups. Group 1 included $4 \mathrm{G}$ patients, 20 female and 20 male, aged between $4 \$$ and 65 years, who underwent CT examination of the lumbosacral spine after complaints of low back pain Group 2 included 25 male patients, aged 20-59 years, with ankylosing spondylitis, without CT findings of prolapsed disc. An Elscint EXEL 240 CT scanner was used. All patients had a preliminar. $250 \mathrm{~mm}$ long surview scan of the lumbosacral ares with a viewing angle of $90^{\circ}$. In each intervertebrat space the tilt of the gantry was planned parallel the disc space. The width of the slices was $5 \mathrm{~mm}$ with $4 \mathrm{~mm}$ increment. A circle diameter of $140 \mathrm{~m}$ 角 was used with matrix $340 / 340$ pixels.

\section{Results}

All patients in group 1 had normal CT scans, and mo calcifications of the ligamenta flava were found. The mild spondylarthritic changes found in some of the patients were consistent with their age. Patients wit便 senile vertebral ankylosing hyperostosis were not included in this group.

All the patients in group 2 had findings of sacroiliitis and 'squaring' of the lumbar vertebrae of conventional radiographs. The older patients hat syndesmophytes and ossifications of the spina ligaments, producing 'bamboo spine'. All the patien in this group had juxta-articular osteoporosis around the sacroiliac joints. In 23 patients $(92 \%)$ calcif cations of the ligamenta flava were demonstrated 
various levels, from $\mathrm{L} 3$ to $\mathrm{S} 1$. In the younger patients (below the age of 25 years), suffering from the disease for a considerably shorter duration of time, these calcifications were fine and not associated with calcifications of other spinal ligaments. In older patients, with a longer duration of the disease, the calcifications of the ligamenta flava were coarse and not necessarily associated with calcifications and ossifications of other spinal ligaments. In two patients coarse calcifications of ligamenta flava resulted in clinical symptoms of spinal stenosis (Fig. 1). Ligamenta flava calcifications or ossifications at more than one level (Fig. 2) were found in 12 patients. Eleven patients in this group also underwent axial CT scan of the cervical spine, which showed ligamenta flava calcifications in five of them (Fig. 1). These five patients had calcified or ossified spinal ligaments in the cervical spine, demonstrated on conventional radiographs.
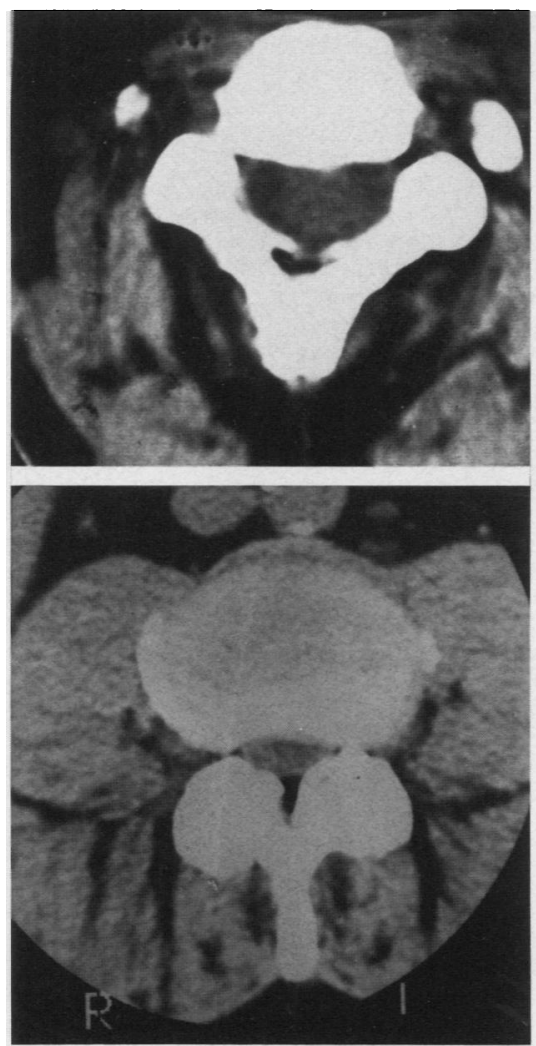

Fig. 1 A 53 year old patient with ankylosing spondylitis and neurogenic intermittent claudication. Calcifications of the ligamenta flava (upper image). Coarse ossification of the ligamenta flava at the level of L3, causing narrowing, predominantly of the transverse diameter of the spinal canal (lower image).
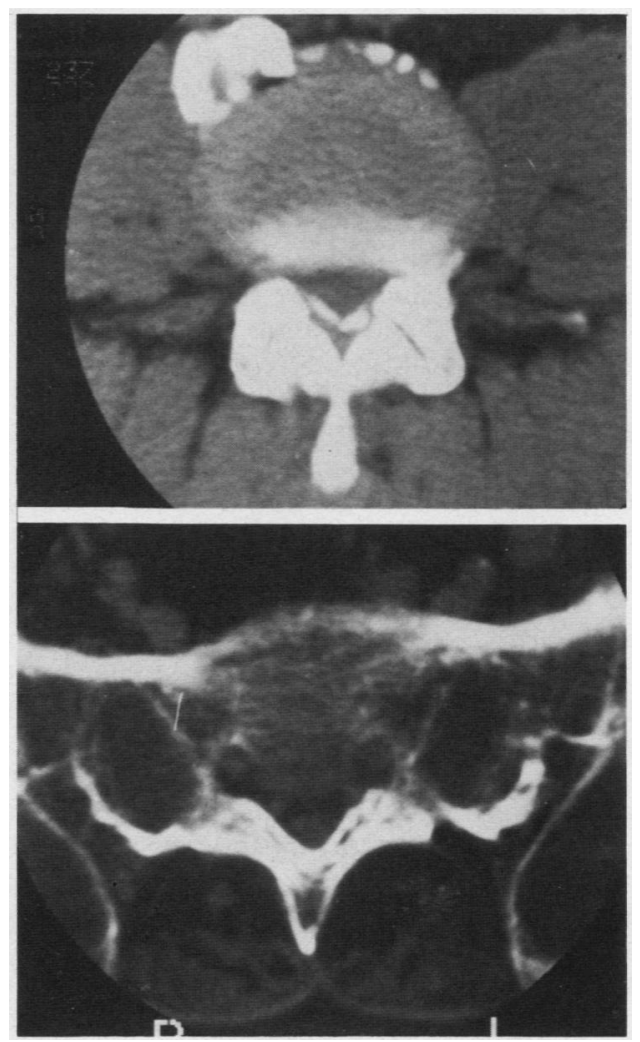

Fig. 2 A 42 year old man with ankylosing spondylitis. Right anterior syndesmophyte and calcified ligamenta flava at the level of L3-4 (upper image). Calcified ligamenta flava at the level of S1 and juxta-articular sacral osteoporosis near the sacroiliac joints (lower image).

\section{Discussion}

Calcification of the ligamenta flava in the lumbosacral region is not sex dependent. Age probably plays a part when calcifications are already present. These calcifications may become coarser and more ossified with age. The lack of ligamenta flava calcifications in otherwise normal CT examinations is obvious in group 1 , in which patients older than 40 years were selected. Also obvious is the high percentage of calcifications in group 2 . They are seen at an early stage of the disease and are not associated with calcifications in other spinal ligaments. At this stage they can be of diagnostic significance when other symptoms are insufficient for the diagnosis. In older patients, with a longer duration of the disease, these calcifications become coarser, more ossified, and can result in spinal stenosis. Usually, in such patients with ankylosing spondylitis, calcifications 
and ossifications of other spinal ligaments are also seen in the remainder of the spine. The calcifications demonstrated in the cervical ligamenta flava in this group are probably an expression of the general process of spinal ligament calcifications and can be useful in the early diagnosis of ankylosing spondylitis.

Spinal soft tissue calcifications and spinal stenosis in ankylosing spondylitis are reported, but there has been no separate study of the ligamenta flava. ${ }^{18-21}$

The aetiology of calcification remains unclear. In inflamed joints, calcium pyrophosphate dihydrate has been found, and the phenomenon has been called 'pseudogout syndrome'. ${ }^{22}$ Chondrocalcinosis also seems to arise in various conditions, such as hereditary haemochromatosis, hyperparathyroidism, diabetes mellitus, and gout. ${ }^{13} 23$ Ligamenta flava calcification, which is a non-specific phenomenon, could well result from other conditions, as in the cases discussed in this study.

Today there is no doubt that CT scanning is the best procedure for the demonstration of ligamenta flava calcifications. This demonstration could be of greater importance in the diagnosis of spinal conditions. It provides important information to the physicians performing surgery for decompression of the spinal canal. This information can also warn the anaesthesiologist before the insertion of the needle for epidural anaesthesia.

We are convinced that, if demonstrated, ligamenta flava calcifications should be noted in the radiologist's report.

\section{References}

1 Polgar F. Ueber interarkuelle Wirbelverkalkung. Fortschritte auf dem Gebieteder Rontgenstrahlen 1929; 40: 292-8.

2 Yamagushi M, Tamagake S, Fujita S. A case of ossification of the ligamentum flavum causing thoracic myelopathy. Orthopaedic Surgery (Tokyo) 1960; 11: 951-6.

3 Koizumi M. Three cases of spinal cord paralysis provided by ligamenta flava ossification. Rinsho Kyobu Geka 1962; 17: 1181-8.

4 Yanagi T, Kato H, Shiozawa Z, Yasuhara N, Kanematzu H. Neurologic disorders caused by ossification of the thoracic spine: analysis of $\mathrm{X}$-ray picture and diagnostic significance. Rinsho Shinkeigaku 1972; 12: 562-70.

5 Kodama T, Okubo K. Matsukado Y. Myelopathy due to ossified ligamenta flava in the lower thoracic region. No Shinke Geka 1979; 7: 863-7.

6 Omojola M F. Cardoso E R. Fox A J, Drake C G, Durwart Q J. Thoracic myelopathy secondary to ossified ligamentur flavum. J Neurosurg 1982; 56: 448-50.

7 Miyasaka K. Kaneda K. Ito T. Takei H, Sugimoto S. Tsuru M Ossification of spinal ligaments causing thoracic radiculomyelo pathy. Radiology 1982; 143: 463-8.

8 Nagashima C. Myelopathy due to ossification of the posteriớp longitudinal and the yellow ligament. Saigai Igaku 1975: 18 $671-83$

9 Hiraoka S. The ossification of the ligamentum flavum of thet spinal foramina. Geka no Ryoiki 1955; 3: 6-11.

10 Nanko S. Takagi A. Mannen, T. et al. A case of cervic radiculo-myelopathy due to calcification of ligamentum flavum Neurol Med Chir (Tokyo) 1976; 4: 205-10.

11 Kamakura K. Furukawa T, Takassu T, Mannen T, Toyokuta Y. Cervical myelopathy due to ossification of ligamenta flava. Rinsho Shinkeigaku 1978; 18: 96-102.

12 Jyotoku Z, Harada H. A case of cervical myelopathy due to calcification of the ligamentum flavum. Rinsho Seikei Gek $\vec{a}$ 1980; 15: 708-12.

13 Kawano K. Yoshida S. Ohwada T, et al. Cervical radiculœ myelopathy caused by deposition of calcium pyrophospha? dihydrate crystals in the ligamenta flava. J Neurosurg 1980; 5 279-83.

14 Kida M, Tabata S. Calcified mass in the cervical ligamenta flavi as a cause of cervical myelopathy. Rinsho Seikei Geka 1981; 100 $310-3$.

15 Kure M. Clinical significance of the calcification of cervictil ligamenta flava. J Japan Orthop Assoc 1980; 54: 1224-5.

16 Masaomi K. Itsushi B, Tadayoshi S. Myelopathy due ossification of the ligamentum flavum of the cervical spine. report of two cases. Spine 1981; 6: 553-9.

17 Nakajima K, Miyaoka M, Sumie H. Nakazato T, Ishii Cervical radiculomyelopathy due to calcification of the ligamenta flava. Surg Neurol 1984; 21: 479-88.

18 Bowie E A, Glasgow G L. Cauda equina lesions associated wi $\mathbb{\text { }}$ ankylosing spondylitis. $\mathrm{Br}$ Med $J$ 1961; ii: 24-7.

19 Matthews W B. Neurologic complications of ankylosing spo dylitis. J Neurol Sci 1968; 6: 561-73.

20 Russell M L, Gordon D A, Ogryzlo M D. McPhedran R S. TR cauda equina syndrome of ankylosing spondylitis. Ann Interh Med 1973; 78: 551-4.

21 Luken M G, Patel D V, Ellman M H. Symptomatic spin stenosis associated with ankylosing spondylitis. Neurosurgeg 1982: 11: 703-5.

22 McCarty D J Jr, Kohn N N, Faieres Y S. The significance of calcium phosphate crystals in the synovial fluid of arthrio patients with 'pseudogout syndrome'. I. Clinical aspects. A Intern Med 1962; 56: 711-32.

23 Miyasaka K, Kaneda K, Sato S, et al. Myelopathy due ossification or calcification of the ligamentum flavum: radiolo and histologic evaluations. AJNR 1983; 4: 629-32. 